\title{
AÇÕES SOCIAIS E OS SERVIÇOS DE SAÚDE PUUBLICA DOS MUNICÍPIOS MEMBROS DA COMISSÃO INTERSETORIAL REGIONAL - CIR - ITAPEVA (SP)
}

\author{
Djair Picchiai ${ }^{1}$; Renata Corrêa Deppa ${ }^{2}$.
}

\begin{abstract}
Resumo
Este artigo apresenta um estudo sobre ações sociais e os serviços de Saúde Pública dos quinze municípios que compõem a Comissão Intersetorial Regional (CIR) de Itapeva - SP. É um estudo de caso composto por aplicação de um questionário sobre a percepção dos usuários dos serviços dos Postos de Saúde. Discorre sobre os conceitos de empreendedorismo social, histórico dos serviços, estrutura e funcionamento do SUS e gestão em Saúde. Descreve aspectos da estrutura da saúde pública no Estado de São Paulo e dos municípios que compõem a CIR de Itapeva SP. Com base nos resultados dos questionários respondidos pelos usuários e uma apuração de indicadores sociais e de Saúde Pública dos municípios da CIR Itapeva e de municípios com referencial de excelência em Saúde Pública no Brasil, a pesquisa aponta que há uma percepção de ações sociais desenvolvidas nos municípios da CIR Itapeva - SP, porém, o envolvimento dos colaboradores dos serviços de Saúde Pública ainda é limitado. Aponta que uma cobertura ampla da Atenção Básica é um dos principais fatores para melhoria nos índices de desempenho em saúde pública no município.
\end{abstract}

Palavras-chave: Ações sociais; Empreendedorismo Social; Saúde Pública.

\begin{abstract}
This article presents a study about social action and public healthcare services in the 15 municipalities that integrate Itapeva's Intersectoral Regional Commission (CIR) of the state of São Paulo. It is a case study with an application of a survey with the users of public health centers. It explores the concepts of social entrepreneurship, the structure and practices of SUS. It also describes structural aspects of healthcare services in the state of São Paulo and in the municipalities that integrate Itapeva's Inter sectoral Regional Commission (CIR). It presents a diagnosis based on the results of questionnaires from the public healthcare users, and a proposal for evaluating social and social healthcare indicators of the municipalities of CIR Itapeva in comparison with indicators from cities
\end{abstract}

\footnotetext{
${ }^{1}$ Professor da Fundação Getúlio Vargas EAESP-FGV; membro do Departamento de Administração Geral e Recursos Humanos desde 1987. Docente pesquisador permanente dos programas de Doutorado Acadêmico e de Mestrado Profissional em Administração da FACCAMP.

${ }^{2}$ Mestranda pela FACCAMP e Professora na Faculdade Itararé.
} 
that are reference for excellence in public healthcare in Brazil. It shows as result the development of social actions in the municipalities of CIR Itapeva, however, involvement from public healthcare contributors is still limited. It also shows that a wide implementation of basic attention programs, that encourage seeking healthcare early in life, is one of the main factors for improving the indicators of public healthcare performance in a municipality

Keywords: Social Action; Social Entrepreneurship; Public Healthcare; Healthcare.

\section{Introdução}

Muitos trabalhos na área da saúde pública visam aperfeiçoar as políticas sociais mediante a realização de propostas para uma melhoria da prestação dos serviços a uma comunidade (CAMPOS; PRESOTO; SOUZA, 2012). Este artigo aborda as ações sociais na visão dos usuários dos serviços de saúde pública nos 15 municípios da CIR - Itapeva $-\mathrm{SP}$.

A pesquisa está delimitada a uma área geográfica e administrativa de um colegiado de um Departamento Regional de Saúde (DRS) que compõem a CIR - ItapevaSP. Trata-se de um estudo em 15 municípios que possuem características semelhantes em relação ao porte, dados socioeconômicos e estrutura de serviços de saúde.

Nem todos os usuários da amostra de pesquisa responderam à pesquisa, o que torna os resultados limitados apenas aos respondentes. $\mathrm{O}$ trabalho apresenta um modelo teórico sobre empreendedorismo social, gestão em saúde e estrutura e organização do SUS.

O estudo de caso apresenta os dados de um roteiro de pesquisa com usuários dos serviços de saúde pública. E, por fim, aborda um comparativo dos indicadores socioeconômicos e de saúde dos 15 municípios da CIR - Itapeva - SP, com municípios que possuem as maiores notas do índice de Desempenho do SUS (IDSUS).

O mecanismo demonstrou que as condições socioeconômicas existentes no município se refletem na qualidade da saúde da população. Porém, pode-se mencionar que a ampla cobertura de equipes na Atenção Básica pode fazer a diferença na assistência à saúde, proporcionando um maior acesso à população. 


\section{Modelo Teórico}

A amplitude do setor governamental e sua estrutura administrativa burocrática influenciaram na estagnação do Estado em suas atividades principais, como a saúde, a educação, a segurança, os transportes públicos e o saneamento básico (TACHIZAWA, 2014).

Em contraponto à passividade de muitos gestores públicos e membros da sociedade civil em geral, indivíduos começaram a aplicar princípios de administração para alcançar fins sociais, questionando o status quo de uma maioria excluída socialmente. Estes indivíduos engajados na mudança social passaram a realizar a atividade denominada atualmente como empreendedorismo social (BORNSTEIN, 2005).

Embora sempre tenham existido pessoas que realizaram ações de empreendedorismo social ao longo dos tempos, a presença das mesmas começou a ser percebida devido às inúmeras atividades inovadoras desenvolvidas com o intuito de mudar uma curva de "estagnação social" na sociedade em que vivem principalmente no final do século XX e início do século XXI (DOLABELA, 2008; BORNSTEIN, 2005).

Os conceitos de empreendedorismo social na literatura acadêmica não apresentam um consenso, assim como ocorre com o empreendedorismo tradicional. Porém, a essência da atividade está em sua própria nomenclatura - o social (BORNSTEIN, 2005; OLIVEIRA, 2008; CRUZ, 2013). É uma atividade organizada que tem por objetivo promover ações para melhorar a qualidade de vida de uma população e para reduzir os efeitos negativos da pobreza (NICHOLLS, 2006). Visa também numa escala maior, melhorar a saúde e o bem-estar das pessoas, em especial dos países menos desenvolvidos, ajudando-as a deixar a condição de pobreza extrema (GATES FOUNDATION, 2016).

De maneira pontual, as ações de empreendedorismo social começaram aos poucos a demonstrar que a responsabilidade pelas questões ligadas a desigualdade social e pobreza não deveria se limitar ao Estado, e que deveriam ser tratadas como uma responsabilidade coletiva. Começou assim uma "Revolução Silenciosa" do empreendedorismo social que não teve mais limites e nem fronteiras (SOLA, 2011).

A prioridade do empreendedorismo social é promover a justiça social pelo combate à pobreza, promovendo a emancipação social do ser humano, ou seja, a capacidade do mesmo de obter seu sustento e de sua família mediante um trabalho digno que lhe proporcione os rendimentos necessários para atender as necessidades básicas do cotidiano (NICHOLLS, 2006; FISCHER, 2011). Diferente do empreendedorismo tradicional, o foco não é o lucro, a "riqueza" para o empreendedorismo social é a melhoria das condições sociais (DEES, 2001). 
Desse modo, o empreendedorismo social tem como público-alvo a sociedade civil, em parceria com os demais segmentos (setor privado, setor público e comunidade em geral), pois somente com a cooperação entre vários segmentos que se consegue trazer uma contribuição significativa para todos os envolvidos (AUSTIN, 2001). Quanto aos aspectos positivos do empreendedorismo social em uma comunidade, pode-se citar a inclusão social, a distribuição mais igualitária de renda, o acesso a uma formação profissional para uma posterior inserção no mercado de trabalho, a melhoria nas condições de saúde em geral, e do meio ambiente dentre outros aspectos (LEAL; FREITAS; FONTENELE, 2015; BAGGENSTOSS; DONADONE, 2013; BORNSTEIN, 2005).

Segundo Oliveira (2008) há três tipos de organizações que promovem o empreendedorismo social: aquelas que trabalham num nível estratégico e tático, de forma sustentadora, capacitadora e divulgadora do empreendedorismo social; aquelas que interveem diretamente numa realidade local, ou seja, que são operacionais por executar ações sociais utilizando conhecimento técnicos de gestão; e aquelas que atuam em todos os níveis. Por exemplo, a Fundação Bill e Melinda Gates (em inglês Bill \& Melinda Gates Foundation), atua tanto no nível estratégico e tático, como no nível operacional, fato este que a torna uma das fundações de maior relevância do mundo, pois atua na pesquisa, financiamento e na distribuição de vacinas e medicamentos, para combater doenças como a AIDS, tuberculose e a malária em diversos países (GATES FOUNDATION, 2016). Como exemplo de organizações que atuam no nível estratégico e tático, pode-se mencionar as internacionais Ashoka e Foundation Schwabque, que dão um suporte técnico no desenvolvimento de entidades de empreendedorismo social em diversos países, sendo que organizações locais executam as ações de empreendedorismo social nas comunidades onde estão inseridas. No Brasil, pode-se citar o exemplo do Instituto Ethos, que atua na sensibilização e mobilização de empresas para uma gestão socialmente responsável (INSTITUTO ETHOS, 2016). E aqueles que interveem diretamente em uma realidade social são os empreendedores sociais.

Assim, empreendedores sociais promovem o desenvolvimento social por realizar ações relacionadas ao combate à fome e à desnutrição, combate ao abuso de drogas, combate e prevenção de violência, assistência à saúde e educação, promoção da cultura local em suas diversas manifestações, dentre outras (CRUZ, 2013).

A assistência à saúde é um tema complexo, o qual igualmente para a sociedade mundial, pois trata-se de uma necessidade básica do ser humano, e que não consegue ser suprida de maneira satisfatória pelo Governo. No Brasil, apesar de existir uma complexa estrutura de saúde pública, ainda não se consegue oferecer na totalidade um serviço digno e de qualidade à população. Para entender melhor essa questão, a seguir apresenta-se um relato do Sistema Único de Saúde - SUS, e procurar-se-á verificar posteriormente as ações sociais existentes entre os colaboradores da saúde pública. 
O Sistema Único de Saúde (SUS) é um conjunto de ações e serviços da Gestão Pública, organizado em redes regionalizadas, e distribuídas em todo o território nacional. A gestão do SUS é responsabilidade de todas as esferas de governo - Federal, Estadual e Municipal (BRASIL, 2004).

A saúde é um direito universal e fundamental do ser humano, estabelecido na Declaração Universal dos Direitos Humanos (DUDH) de 1948 e assegurado pela CF de 1988 (REIS; ARAÚJO; CECÍLIO, 2012).

Os princípios doutrinários do SUS são a universalidade, a equidade e a integralidade. A universalidade pressupõe a garantia de acesso de toda a população aos serviços de saúde, em todos os níveis de assistência, sem qualquer tipo de privilégios ou discriminação (AGUIAR, 2015). A equidade procura assegurar a disponibilidade dos serviços de saúde, considerando as especificidades de indivíduos e de grupos populacionais, priorizando aqueles que apresentam uma maior vulnerabilidade social, e uma maior necessidade de atendimento dos serviços de saúde (AGUIAR, 2015). A integralidade é definida de acordo com o texto da LOS n. 8.080 como "um conjunto articulado de ações e serviços preventivos e curativos, individuais e coletivos, exigido para cada caso, em todos os níveis de complexidade do sistema" (AGUIAR, 2015).

Além dos princípios doutrinários, há os princípios organizativos, que incluem a descentralização, a regionalização e hierarquização do sistema e a participação e controle social (AGUIAR, 2015).

A descentralização envolve a transferência de responsabilidades como planejamento, tomada de decisão e gestão, bem como a transferência de recursos financeiros da esfera Federal para os estados e municípios (FLEURY, 2014). O processo de descentralização também dá ênfase a outro processo, o de municipalização (AGUIAR, 2015). A regionalização refere-se a uma distribuição equilibrada dos serviços de saúde no país, ou seja, trata-se da organização do SUS em base territorial e populacional. A hierarquização refere-se à organização dos níveis de atenção à saúde por complexidade: básica, média e alta, estabelecendo, que o acesso inicial do usuário deve ser pela Atenção Básica (AGUIAR, 2015). A participação é uma garantia constitucional de que todos os segmentos da população organizados por entidades representativas podem e devem participar do processo de formulação de políticas públicas, do controle e de sua execução, em todos os níveis de governo (AGUIAR, 2015).

O controle social é uma garantia de participação da população nos conselhos, e conferências no processo de gestão pública, desde a elaboração de políticas de saúde até a fiscalização, e controle das mesmas (AGUIAR, 2015). 
Conforme o decreto 7.508/11, a assistência à saúde ocorre na Rede de Atenção à Saúde pelo referenciamento numa rede regional e interestadual aos usuários, conforme as pactuações feitas pelas Comissões Intergestores, que são: Comissão Intergestores Tripartite (CIT), que é a instância de pactuação das três esferas de Governo, formada por representantes do Ministério da Saúde (MS), do Conselho Nacional de Secretários de Saúde (CONASS), e do Conselho Nacional de Secretários Municipais de Saúde (CONASEMS); Comissão Intergestores Bipartite (CIB), que é a instância estadual de pactuação, formada pelo gestor estadual e pelos gestores municipais de saúde; e Comissão Intergestores Regional (CIR), que é a instância regional, composta por gestores de uma região de saúde vinculada à Secretaria Estadual de Saúde, nas questões administrativas e operacionais (AGUIAR, 2015).

Para organizar a assistência à saúde dos usuários foi instituída uma Relação Nacional de Medicamentos (RENAME), que é uma padronização de medicamentos indicados para os atendimentos no SUS, mediante protocolos clínicos, e diretrizes terapêuticas em âmbito nacional, sendo que tais medicamentos devem ter obrigatoriamente registro na Agência Nacional de Vigilância Sanitária (Anvisa). Além da RENAME, instituiu-se também a Relação Nacional de Ações e Serviços de Saúde (RENASES), que envolve todas as ações e serviços que os SUS oferece aos usuários. É organizada em cinco grupos:

- Ações e serviços de atenção básica: conjunto de ações de saúde desenvolvidas nas Unidades Básicas de Saúde (UBS), tanto no âmbito individual quanto coletivo, que visam a promoção e a proteção da saúde, bem como a prevenção, diagnóstico, tratamento, reabilitação, e manutenção da saúde dos usuários. É o primeiro contato dos usuários na Rede de Atenção à Saúde. A Política Nacional de Atenção Básica tem na Saúde da Família sua estrutura prioritária, onde cada unidade de saúde deve atender uma demanda populacional de um território adstrito (BRASIL, 2012).

- Ações e serviços de urgência e emergência: são organizadas pela Rede de Urgência e Emergência (RUE), e são compostas por unidades pré-hospitalares fixas e móveis e unidades hospitalares. A RUE foi instituída pela portaria $\mathrm{n}$. 1.600 de 7 de julho de 2011, que reformulou a Política Nacional de Atenção às Urgências.

- Ações e serviços de atenção ambulatorial especializado e hospitalar, realizados à nível ambulatorial pelos Centros de Especialidades, e por Ambulatórios de Especialidades nos municípios ou na região de saúde que pertencem, mediante agendamento prévio com a Central de Regulação de cada município. O atendimento especializado é classificado como de média complexidade, que dá suporte aos serviços de Atenção Básica (FUNDAP, 2010). Os atendimentos de emergência são realizados pelos hospitais, que devem oferecer atendimento imediato e ininterrupto aos pacientes em estado crítico ou potencialmente crítico. 
As ações e serviços de atendimento de atenção hospitalar são definidos por grau de complexidade, existindo uma classificação quanto à estrutura de atendimento I, II e III.

- Ações e serviços de atenção psicossocial: são desenvolvidas pela Rede de Atenção Psicossocial, que atende pessoas com transtornos mentais graves e persistentes, decorrentes de doenças crônicas natas ou adquiridas, e pessoas com problemas relacionados ao uso abusivo e/ou dependência de álcool, e outras drogas que interferem nas diversas dimensões da vida (família, trabalho, educação, saúde, dentre outras) (BRASIL, 2016). Este atendimento é realizado pelos Centros de Atenção Psicossocial (CAPS), que podem ser implantados em municípios que tenham a partir de 20.000 habitantes. Os CAPS visam oferecer o cuidado centrado nas necessidades das pessoas. Existem várias modalidades de CAPS: CAPS I, CAPS II, CAPS III, CAPS AD, CAPS AD III e CAPS i, que são implantados de acordo com as necessidades da demanda, e do porte do município (BRASIL, 2016).

- Ações e serviços de vigilância em saúde: visam reduzir a morbimortalidade, os fatores de risco associados à saúde, a prevenção e controle de doenças transmissíveis, a vigilância ambiental em saúde, dentre outras ações. Cada município deve ter um setor ou departamento de Vigilância Sanitária (VISA) e Vigilância Epidemiológica (VE) para realizar tais ações.

A gestão em saúde nas esferas de Governo esteve caracterizada de maneira geral, por muitas décadas, pela burocracia, isto é, a autoridade é exercida por um administrador num sistema de hierarquia e regras, que determinam a estrutura e funcionamento da organização (MORGAN, 2007).

A administração burocrática é caracterizada pelos seguintes aspectos: princípio da competência, onde se delimitam tanto as atribuições dos funcionários como se constituem as instâncias; pela hierarquia funcional e sistema de tramitação; pela técnica de documentação e arquivo, onde nenhuma decisão tem eficácia se não se publica de forma oficial, e pela transformação do cargo público em uma profissão (RAMOS, 2008).

Este sistema que data do início do século XX, permitia a realização de tarefas amplas e complexas e, de certa forma, resolvia os problemas fundamentais numa sociedade que tinha um ritmo mais lento, pois as mudanças ocorriam numa menor rapidez (OSBORNE; GAEBLER, 1995).

Porém, essa centralização da autoridade mostrou-se ineficaz com passar dos anos, pois a orientação por meio de regras e regulamentos tornou a gestão inflexível, sem inovações, e sem um compromisso com a excelência (OSBORNE; GAEBLER, 1995). 
A partir da década de 1990, com a criação do SUS, e com o Plano Diretor da Reforma Administrativa do Estado, proposto pelo então ministro da Administração Federal e Reforma do Estado, Luiz Carlos Bresser Pereira em 1995, e colocado em vigência em 1996, procurou-se suplantar a administração burocrática pela administração gerencial, para aumentar a efetividade do Governo na prestação dos serviços públicos, incluindo a saúde (BRASIL, 1995). Assim, a gestão em saúde pública deveria ser estratégica, cooperativa, democrática e solidária (FLEURY, 2014).

O processo de descentralização estabelecido pela lei 8.080/90 que instituiu o SUS, tornou-se um princípio organizativo, pela transferência das funções de planejamento, tomada de decisão e gestão do Governo Federal, para os Estados e Municípios, com o objetivo de formular e implementar políticas mais próximas à realidade dos municípios brasileiros, de acordo com suas necessidades e especificidades (FLEURY, 2014).

A descentralização fortalece o poder local, e promove a inovação nos municípios. Para isso, é imprescindível rever a forma de se executar as ações de saúde, e mudá-las sempre que for necessário, para recuperar a qualidade do serviço público, e garantir a igualdade de acesso dos serviços básicos de saúde a toda a população. Salienta-se que a inovação nos serviços de saúde pública deve relacionar-se "mais a uma mudança de postura e de posicionamento ideológico do que à inovação tecnológica" (FLEURY, 2014, p. 66).

O processo de descentralização trouxe benefícios, como o aumento da cobertura assistencial da atenção básica e o acesso à saúde, e, principalmente tornou a gestão mais democrática e participativa, pois o poder de decisão passou também, a ser levado aos usuários dos serviços de saúde pública (JUNQUEIRA, 1997).

Porém, mesmo com os avanços da gestão descentralizada, continuam os desafios para os municípios, considerando a complexidade de consolidar as políticas de saúde pública num país de vasta extensão territorial, e caracterizado pela desigualdade econômica, social e de organização de serviços de saúde, dentre outras questões (AGUIAR, 2015).

Outro desafio é mudar a cultura existente no sistema público tradicional, que é desenvolvido muitas vezes para atender a conveniência do administrador, e não do cliente, que é o usuário dos serviços de saúde pública (OSBORNE; GAEBLER, 1995). 
O administrador público, em especial, na esfera municipal, deve ter ciência que, ao receber recursos financeiros para seu município, o mesmo tem a obrigação de garantir o acesso a serviços de saúde pública de qualidade aos seus cidadãos, garantindo um sistema resolutivo, seja em seu município, ou em outros de referência regional para atendimentos de saúde pública (JUNQUEIRA, 1996). Isso é um dos direitos básicos garantidos pela Constituição Federal de 1988 que estabelece a saúde como um direito de todos, e dever do Estado (BRASIL, 2008).

O governo precisa se tornar empreendedor, ou seja, ser uma organização em constante processo de aprendizagem, disposta a experimentar novas abordagens e, principalmente, avaliar os resultados dos serviços que oferece aos usuários, direcionando os recursos financeiros e humanos para recuperar a qualidade dos serviços de saúde pública, e garantir o acesso a todos, em especial aos usuários de áreas de maiores níveis de pobreza (OSBORNE; GAEBLER, 1995; FLEURY, 2014). Porém, o ambiente da administração pública nem sempre favorece o empreendedorismo, devido à elevada burocracia, e corrupção existentes no mesmo (PINHO; THOMPSON, 2016).

A avaliação dos resultados ainda apresenta resistência por parte de alguns colaboradores e gestores do SUS. Porém, a avaliação dos serviços resulta em um aprimoramento na qualidade dos mesmos, pois com um diagnóstico é possível minimizar as falhas do sistema, e buscar a excelência no atendimento aos usuários.

Assim, o Governo Federal procurou criar sistemas de avaliação de desempenho dos serviços de saúde pública. Um desses sistemas de avaliação foi instituído pelo SUS em 2011 e colocado em prática em 2012, o Índice de Desempenho do Sistema Único de Saúde (IDSUS), que avalia o desempenho do SUS nos municípios, regiões, estados e no Brasil. Trata-se de um índice composto por 24 indicadores, que avalia o acesso e a efetividade na atenção básica, especializada ambulatorial e hospitalar, e de urgência e emergência. Participam na construção dos índices representantes do Conselho Nacional de Secretários de Saúde (CONASS), Conselho Nacional dos Secretários Municipais de Saúde (CONASEMS), Instituto de Pesquisa Econômica Aplicada (IPEA), Associação Brasileiro de Pós-Graduação em Saúde Coletiva (ABRASCO), Fundação Oswaldo Cruz (FIOCRUZ), Ministério do Desenvolvimento Social, e representantes de cada secretaria do Ministério da Saúde (BRASIL, 2015).

A fonte dos indicadores são: Pacto pela Saúde, Avaliação de Desempenho do Sistema de Saúde Brasileiro (PRO-ADESS), Banco Interamericano de Desenvolvimento (BID), IPEA, Instituto Brasileiro de Geografia e Estatística (IBGE) e experiências internacionais como a Organização Pan-americana (OPAS), a Organização para a Cooperação e Desenvolvimento Econômico (OCDE) e a Agencia para la Investigación y Calidad de Salud (AHRQ) (OLIVEIRA; SELLERA; REIS; 2013). 
A partir desse índice começou-se a diagnosticar efetivamente os municípios e regiões com maiores problemas na oferta, e na qualidade de serviços de saúde pública no Brasil. O objetivo do MS é com base nesses parâmetros, nortear melhor os investimentos, e efetivar melhorias nas políticas de saúde pública, buscando atender com qualidade as necessidades dos usuários (BRASIL, 2011).

A primeira secretaria estadual de saúde foi criada no Estado de São Paulo em 28 de junho de 1947, pelo Decreto-Lei n. 17.339, e era denominada Secretaria de Estado de Negócios da Saúde Pública. Porém, foi em 1967, na gestão do governador Roberto Costa de Abreu Sodré (1967-1971), por meio do Decreto n. 52.182 de 16 de julho de 1969, que houve definição mais estruturada da composição dessa secretaria estadual, que passou a ser denominada como Secretaria de Estado da Saúde (SÃO PAULO. Estado, 1969).

Nesse decreto foram definidas 10 Divisões Regionais de Saúde (DRS) no Estado, modelo que permanece até a atualidade, sendo que em 2016, são 17 DRSs, que estão alistadas abaixo: DRS I - Grande São Paulo; DRS II - Araçatuba; DRS III - Araraquara; DRS IV - Baixada Santista; DRS V - Barretos; DRS VI - Bauru; DRS VII - Campinas; DRS VIII - Franca; DRS IX - Marília; DRS X - Piracicaba; DRS XI - Presidente Prudente; DRS XII - Registro; DRS XIII - Ribeirão Branco; DRS XIV - São João da Boa Vista; DRS XV - São José do Rio Preto; DRS XVI - Sorocaba; e DRS XVII Taubaté.

Essa divisão em regionais de saúde possibilita que, o planejamento, organização e execução e ações de Saúde Pública sejam orientadas de acordo com as especificidades regionais.

A DRS XVI Sorocaba foi criada em 8 de dezembro de 1981. Abrange 48 municípios da região sudoeste e centro sul do Estado de São Paulo que são: Alambari, Alumínio, Angatuba, Apiaí, Araçariguama, Araçoiaba da Serra, Barra do Chapéu, Boituva, Bom Sucesso de Itararé, Buri, Campina do Monte Alegre, Capão Bonito, Capela do Alto, Cerquilho, Cesário Lange, Guapiara, Guareí, Ibiúna, Iperó, Itaberá, Itaóca, Itapetininga, Itapeva, Itapirapuã Paulista, Itararé, Itu, Jumirim, Mairinque, Nova Campina, Piedade, Pilar do Sul, Porto Feliz, Quadra, Ribeira, Ribeirão Branco, Ribeirão Grande, Riversul, Salto, Salto de Pirapora, São Miguel Arcanjo, São Roque, Sarapuí, Sorocaba, Tapiraí, Taquarivaí, Tatuí, Tietê e Votorantim (SÃO PAULO, 2016). A DRS de Sorocaba possui três CIRs sendo: CIR Sorocaba, CIR Itapetininga e CIR Itapeva.

A Comissão Intersetorial de Itapeva é composta por 15 municípios sendo: Apiaí, Barra do Chapéu, Bom Sucesso de Itararé, Buri, Guapiara, Itaberá, Itaóca, Itapeva, Itapirapuã Paulista, Itararé, Nova Campina, Ribeira, Ribeirão Branco, Riversul e Taquarivaí. A coordenação dos serviços de saúde é feita por duas articuladoras, sendo uma responsável pela região Sudoeste e outra pela região do Alto Ribeira (SÃO PAULO, 2016). 
Os membros da CIR são os gestores municipais de saúde, representantes da DRS Sorocaba, representante do Conselho dos Secretários Municipais de Saúde (COSEMS) e outros representantes administrativos da Secretaria Municipal de Itapeva-SP.

A integração dos gestores e da diretoria da DRS tem por objetivo elaborar propostas de aperfeiçoamento das ações de saúde nos diferentes níveis. São realizadas reuniões mensais para o planejamento, discussão, e aprovação de tais propostas.

A região dos municípios da CIR - Itapeva é bem distinta de outras regiões do estado de São Paulo, pois apresenta segundo dados do IBGE (2016), indicadores socioeconômicos pouco expressivos, em comparação com as outras regiões do Estado, conforme será demonstrado nos próximos tópicos.

Os 15 municípios da Comissão Intersetorial Regional de Itapeva -SP, por serem em sua grande maioria (14 municípios) de pequeno porte, possuem na área de saúde pública basicamente serviços de atenção básica, e alguns serviços de especialidades. Vale salientar, que para implantar uma unidade de saúde, é necessário incluir no Plano Plurianual do município, a proposta da unidade, e, que deverá passar em seguida, pela aprovação de várias instâncias: Conselho Municipal de Saúde (CMS), CIR Regional, DRS, e depois para o Ministério da Saúde (MS). A proposta é feita num projeto padrão disponibilizado pelo Ministério da Saúde para os municípios, e que deve ter anexado uma cópia da planta baixa da futura unidade de saúde, feita por um engenheiro civil credenciado do município.

Após a aprovação do projeto, é publicado em portaria oficial a aprovação do mesmo, bem como a disponibilização do recurso financeiro para iniciar a unidade, que deverá ser depositado em uma conta do Fundo Municipal de Saúde (FMS). O município deve disponibilizar uma contrapartida financeira para subsidiar o projeto, junto com o recurso financeiro Federal. É determinado um prazo para a realização da unidade de saúde e, a partir do início de suas atividades, é imprescindível digitar e enviar regularmente no sistema eletrônico de compilação de dados da produção ambulatorial do SUS, o E-SUS, a produção realizada pela unidade de saúde. Caso não seja feito o envio da produção, automaticamente é cancelado o subsídio mensal do Governo Federal para a manutenção da unidade.

Deve-se ressaltar que alguns municípios fazem projetos de unidades de saúde, seja elas de Atenção Básica ou de Atenção Especializada, contudo, devido à falta de planejamento a médio e longo prazo dos recursos financeiros, acabam apenas inaugurando a unidade, sem, contudo, colocá-la em funcionamento para oferecer serviços à população. Assim, nos dados do Cadastro Nacional de Estabelecimentos de Saúde (CNES) constam as unidades que foram feitas, mas não necessariamente que estejam em funcionamento nos municípios. 
Todo município brasileiro precisa ter o mínimo de estrutura administrativa de saúde Pública. Isso envolve ter um setor, departamento, ou secretaria de saúde. Além disso, outros dois serviços essenciais são a Vigilância Sanitária (VISA), Vigilância Epidemiológica (VE), e Central de Regulação, que é responsável pelo agendamento de exames e consultas de especialidades no município ou em outro(s) de referência. Todos os municípios da CIR apresentam essa estrutura administrativa mínima.

Alguns municípios possuem o serviço de Atendimento Móvel de Urgência (SAMU), o que beneficia muito a população nos atendimentos de urgência e emergência até o encaminhamento para uma unidade hospitalar. Esse serviço é administrado pela Central de Regulação Regional do SAMU, que fica no município de Itapeva. Em relação aos hospitais, apenas seis municípios possuem tal serviço; o restante possui apenas serviço de Pronto Atendimento (PA). Deve-se ressaltar que outros municípios apresentam uma estrutura hospitalar, contudo, devido a dívidas atrasadas, falta de recursos humanos (em especial de médicos), insumos e equipamentos, deixaram de ter atendimento hospitalar, e passaram a oferecer apenas pronto atendimento, ficando infelizmente, com parte da estrutura física ociosa.

A Santa Casa de Misericórdia de Itapeva é a referência hospitalar da microrregião, oferecendo serviços inexistentes em outros municípios, como os de Unidade de Tratamento Intensivo - UTI e UTI neonatal, hemodiálise, diagnóstico de imagem por Ressonância Magnética, dentre outros. Foi construída recentemente uma ala nesse hospital para tratamento oncológico, para oferecer tratamento de quimioterapia e radioterapia. A estrutura física ficou pronta no primeiro semestre de 2016, e, no momento aguarda-se recursos financeiros para a aquisição dos equipamentos necessários para oferecer tais serviços à população da microrregião. Atendimentos mais complexos são encaminhados para a referência regional que é o Conjunto Hospitalar Sorocaba (CHS).

Os serviços de atenção básica são considerados a "porta de entrada" da saúde pública de um município. As Unidades Básicas de Saúde (UBS), os Postos de Atendimento de Saúde (PAS) e os Postos de Saúde (PS), são as unidades de saúde tradicionais, que podem oferecer atendimento médico, enfermagem, odontológico, além de serviços como fornecimento de medicamentos, vacinas, pequenos curativos, procedimentos injetáveis, aferição de pressão arterial, dentre outros. Essas unidades não possuem verba específica para arcar com suas despesas, assim, a gestão municipal é que subsidia as mesmas, com recursos financeiros próprios para o pagamento dos salários, e para o fornecimento de insumos. 
Os serviços oferecidos variam de acordo com o porte da unidade, algumas dessas possuem apenas atendimento de enfermagem diariamente, e atendimento médico em dias específicos, por exemplo. Já outras são completas, e oferecem todos os serviços alistados anteriormente. A Estratégia de Saúde da Família (ESF) são as unidades com equipes que atuam num território delimitado geograficamente, e que recebem subsídio específico do governo Federal para pagar parte das despesas com folha de pagamento e insumos. $\mathrm{O}$ modelo de atendimento das ESFs é o padrão estabelecido pelo SUS, desde o final dos anos de 1990, para a Atenção Básica Nacional nos municípios.

Quanto aos consultórios odontológicos isolados nos municípios, referem-se a consultórios inseridos em unidades escolares. No final dos anos de 1970, e início de 1980, preconizava-se no Estado de São Paulo, um modelo de atendimento prioritário ao escolar, nos primeiros anos do ensino fundamental. Assim, foram instalados centenas de gabinetes dentários, como se denominavam os consultórios odontológicos na época. Porém, esse modelo entrou em desuso a partir da implantação do SUS em 1990, pois o atendimento de saúde incluindo o odontológico, deveria ser oferecido a todos na unidade de saúde, que deve oferecer atendimento igualitário para todas as faixas etárias. Itararé é um dos poucos municípios que ainda trabalha com esse modelo tradicional de atendimento ao escolar.

A unidade odonto móvel é uma unidade móvel de atendimento odontológico, modelo que faz parte da Política Nacional de Saúde Bucal, do Governo Federal para municípios com extensa área rural. No caso da região da CIR Itapeva, foram publicadas várias portarias autorizando o envio de unidades móveis para atendimento odontológico, contudo, apenas o município de Itaberá recebeu a unidade de fato.

Dois municípios possuem laboratório municipal, os outros terceirizam os serviços de exames laboratoriais. Quanto a distribuição de medicamentos, apenas dois municípios possuem uma farmácia própria; nos outros, as próprias unidades de saúde ou então a sede administrativa de saúde pública do município disponibiliza um dispensário de medicamentos, sendo obrigatória, a presença de um(a) farmacêutico(a) responsável no mesmo.

Além da Atenção Básica, o município deve organizar atendimentos especializados à sua população. Devido ao porte, alguns municípios não possuem recursos físicos, e principalmente, recursos humanos para atuarem nos atendimentos especializados e, assim, utilizam outros municípios como referência para tais atendimentos. Porém, com o crescimento e desenvolvimento do município, o mesmo pode habilitar-se para instalar alguns ambulatórios especializados. O Ambulatório de Especialidades (AME), o Centro de Atenção Psicossocial (CAPS) e o Centro de Especialidades Odontológicas (CEO) são referências importantes no atendimento à saúde. Alguns possuem abrangência local, como o CAPS e o CEO, e outros como o AME possuem abrangência regional, sendo este 
último citado, considerado pela maioria dos municípios da CIR Itapeva - SP, como um serviço de excelência na região. Esses serviços alistados recebem subsídio financeiro mensal do Governo Federal, para custear parte da folha de pagamento e dos insumos.

Os ambulatórios de especialidades, materno-infantil, de saúde mental, de doenças infectocontagiosas, e de saúde da mulher, presente em alguns municípios, são iniciativas próprias, que são custeadas com recursos municipais. O Instituto do Câncer, que funcionará na Santa Casa de Itapeva-SP, embora esteja cadastrado no CNES, ainda não está em funcionamento. A Academia Municipal de Saúde, que consta no CNES dos municípios de Itapeva e Itararé estão prontas e foram inauguradas, porém não estão oferecendo serviços à população.

Quanto aos serviços de fisioterapia, apenas o município de Itararé possui uma unidade específica; os outros municípios que possuem tal serviço, oferecem o mesmo dentro de uma unidade de saúde ou então, encaminham sua população para o serviço de referência, que é o AME em Itapeva.

Além das unidades de Saúde Pública de Atenção Básica e Especializada, estão cadastradas no CNES outras unidades que, embora não sejam específicas de saúde, oferecem atendimento gratuito a população, subsidiado com recursos municipais, doações e outros recursos. As Associações de Pais e Amigos dos Excepcionais (APAE), por exemplo, oferecem em algumas de suas unidades os seguintes atendimentos: médico, odontológico, enfermagem, psicológico, fisioterápico, terapia ocupacional, nutricional, dentre outros. Alguns municípios como forma de apoiar o trabalho de tais entidades, disponibilizam profissionais do quadro de funcionários estatutários para trabalhar nesses locais. Essa produção ambulatorial é lançada no sistema E-SUS, e, por conseguinte, o município recebe recursos por tal produção. Apenas os municípios de Itapeva, Itararé e Buri possuem esse tipo de atendimento de saúde, fora de estabelecimentos de saúde pública.

\section{Metodologia}

Em relação aos fins e objetivos, pode-se classificar a pesquisa como exploratória que objetiva o aprimoramento de ideias e as descobertas de intuições, mediante um levantamento bibliográfico e entrevistas com pessoas que apresentam experiências práticas com o problema pesquisado (GIL, 2009).

O levantamento bibliográfico dessa pesquisa exploratória apresenta um modelo teórico com base em citações de autores nacionais e internacionais, relacionado aos temas Empreendedorismo Social, desenvolvimento local, estrutura do SUS, organização da assistência à saúde, gestão em saúde, organização da saúde pública do Estado de São Paulo, DRS XVI Sorocaba, dados dos municípios da CIR - Itapeva - SP referente a indicadores sociais, estrutura de saúde pública e indicadores do IDSUS. 
A metodologia utilizada na pesquisa foi mista, utilizando pesquisa qualitativa e quantitativa para entender as características da amostra estudada.

Por se tratar de um estudo de caso, a pesquisa qualitativa foi necessária para entender fenômenos sociais complexos, como o que se pretende abordar nesse trabalho, que são as ações de colaboradores da saúde pública de uma determinada região. O estudo de caso permite obter características significativas de eventos da vida real e contribui para o conhecimento dos pesquisadores de "fenômenos individuais, grupais, organizacionais, sociais, políticos [...]" e outros correlatos (YIN, 2010, p. 24). No aspecto qualitativo, o estudo de caso foi composto pela técnica de entrevistas, classificadas por Bardin (2011), como entrevistas semidiretas ou semiestruturadas, pois as informações foram obtidas por e-mail e, em sequência, analisadas pela pesquisadora.

O tratamento dos dados da pesquisa qualitativa foi realizado pela técnica de análise de conteúdo, envolvendo três fases: a primeira é a pré-análise, envolvendo a seleção do material e definição dos procedimentos; a segunda é a exploração do material, abrangendo a execução dos procedimentos planejados e a terceira é o tratamento dos dados coletados, realizando-se a intepretação e a inferência a partir dos mesmos (VERGARA, 2012).

A metodologia também é considerada quantitativa pela realização de um levantamento (Survey) com usuários dos serviços de saúde da região pesquisada. O Survey foi composto por perguntas fechadas de múltipla escolha e de estimação e avaliação (MARCONI; LAKATOS, 2007). A compilação dos dados quantitativos envolverá a aplicação de estatística descritiva com o uso do editor Excel.

\section{Análise}

Para identificar a percepção dos usuários das ações sociais e dos serviços de saúde pública dos postos de saúde da CIR Itapeva, foi realizado um roteiro de pesquisa com o uso de um questionário, com quatro perguntas fechadas ou dicotômicas e perguntas de múltipla escolha (OLIVEIRA, 2003). A aplicação dos questionários nos 15 municípios foi feita por meio de redes sociais e e-mail, sendo esta última, a mais utilizada. Inicialmente, foram enviados 500 questionários, após desconsiderar os que não foram retornados ou respondidos erroneamente, foram compilados 274 questionários. Levou-se 30 dias (25/10/2016 a 25/11/2016) para realizar esta etapa da pesquisa.

Sobre a composição da amostra analisada, foi levantado que $82 \%$ dos entrevistados são mulheres e $18 \%$ homens, sendo que a maioria se encaixava em duas faixas etárias: a primeira, representando $40 \%$, é composta de indivíduos com idades entre 18 e 25 anos, já a segunda, 39\%, abrangia pessoas de 26 a 35 anos. 
Quanto ao grau de escolaridade, $4 \%$ possui pós-graduação, 32\% ensino superior, $58 \%$ ensino médio e $6 \%$ ensino fundamental. Assim, percebe-se que pessoas de todos os graus de instrução vão às unidades em busca de atendimentos diversos, independente do grau de instrução.

O serviço mais procurado foi à consulta médica (79\%), seguido pelos procedimentos (35\%), farmácia (31\%), consulta de enfermagem (27\%), realização/atualização do cartão SUS e consulta odontológica (21\%).

Devido ao alto custo de consultas médicas e de medicamentos nos serviços particulares e, também, a falta de acesso a convênios, a população busca, com muita frequência, tais serviços nos postos de saúde. Muitos, ainda, desconhecem a existência de serviços de atendimento odontológico nos postos, explicando a baixa demanda pela operação.

Para os usuários dos postos de saúde foi solicitada uma avaliação dos serviços realizados. Primeiramente, sobre o horário de atendimento, $10 \%$ consideraram excelente, $55 \%$ bom, $25 \%$ regular e $10 \%$ ruim. Essas unidades de saúde iniciam suas atividades em média às $7 \mathrm{~h} 00$, sendo que a grande maioria das consultas médicas é agendada.

Porém, em relação ao tempo de espera, a avaliação foi negativa - 56\% responderam que o tempo de espera é regular ou ruim, ante os $39 \%$ que disseram ser bom. Essa é uma questão problemática nos postos de saúde e que persiste há muito tempo.

Os possíveis motivos dessa insatisfação da avaliação do tempo de espera são: o atraso de profissionais, em especial de médicos, para realizarem o atendimento; o grande número de usuários que são agendados no mesmo horário, o que faz com que a préconsulta (aferição de pressão arterial, peso, confirmação de dados cadastrais, dentre outros procedimentos) realizada pelo técnico ou auxiliar de enfermagem seja demorada e a falta de organização do atendimento pela unidade, pois as consultas poderiam ser agendadas em horários diferentes, o que reduziria o tempo de espera dos usuários.

Sobre a avaliação da estrutura física dos postos de saúde, $9 \%$ avaliaram como excelente, $45 \%$ disseram ser boa, $32 \%$ regular e $14 \%$ ruim. Deve-se ressaltar que as unidades de saúde mais novas apresentam uma estrutura física melhor, uma melhor distribuição dos espaços e, também, são melhores equipadas. Os municípios, ainda, possuem unidades de saúde em prédios muito antigos e, muitas vezes pequenos, o que causa desconforto tanto para os colaboradores, como para os usuários. 
Um item importante avaliado pelos usuários foi a qualidade do atendimento. Os resultados formam positivos, pois $15 \%$ consideraram a qualidade excelente, e $52 \%$ como boa. Isso mostra que apesar dos problemas existentes nos postos de saúde, a qualidade de parte dos atendimentos é satisfatória. Porém, o fato de $26 \%$ avaliarem como regular e $7 \%$ como ruim significa que há muito a ser melhorado na prestação de serviços de saúde à população.

Em relação aos 15\% dos usuários que afirmaram não ter utilizados os serviços dos postos de saúde, indagou-se aos mesmos sobre os motivos. Os resultados são: $68 \%$ não precisaram, 23\% utilizam serviço de saúde particular ou de convênio, $7 \%$ ficaram insatisfeito com os serviços do posto de saúde e não quis mais utilizar os mesmos e $2 \%$ afirmou que desconhece os serviços ofertados.

Foi perguntado junto aos usuários sobre as visitas domiciliares dos Agentes Comunitários de Saúde (ACSs). Vale ressaltar que o acompanhamento dos ACSs nos domicílios deve ser uma das bases da estruturação do planejamento das ações de Saúde Pública na Atenção Básica nos municípios. O ACS é uma espécie de intermediador entre a família e o posto de saúde, sendo responsável pelos cadastros das famílias e acompanhamento das condições de saúde da comunidade, registrando as mesmas nos prontuários dos usuários pertencentes à unidade de saúde.

Sobre a frequência da visita dos ACSs, $43 \%$ dos pesquisados afirmaram que recebem regularmente as visitas, $32 \%$ raramente, $20 \%$ afirmaram que nunca receberam a visita, e 5\% não souberam informar. Isso demonstra, de acordo com as respostas dos pesquisados, que nem sempre a visita dos ACSs é regular nas áreas dos municípios que trabalham. Assim, é preciso investigar as possíveis causas da falta de regularidade das visitas dos ACSs nos domicílios, dada a importância da atuação desses profissionais na Atenção Básica dos municípios.

Aos que receberam a visita de um ACS, 75\%, foi indagado sobre quais informações são apresentadas nas visitas domiciliares. Cerca de $52 \%$ dos pesquisados afirmaram que recebem as visitas sob o intuito de vistoria do domicílio para prevenção de doenças, como a dengue, e 50\% dos entrevistados receberam informações relacionadas ao cadastro de sua família na unidade de saúde. Outras opções assinaladas foram: orientação verbal sobre os serviços do posto de saúde (34\%), orientação verbal sobre prevenção e tratamento de doenças $(38 \%)$ e orientação com o uso de material impresso sobre prevenção e tratamento de doenças (15\%). Vale ressaltar que a educação em saúde é uma das funções do ACS, e a pesquisa demonstra que nesses municípios os mesmos procuram fazer a sua parte, porém, precisam usar mais material informativo sobre a prevenção e tratamento de doenças, já que esse tipo de trabalho educativo envolve, também, deixar informações de leitura aos usuários. O uso de material impresso com leitura informativa e fotos, distribuído à população juntamente com a orientação verbal 
dos ACSs, pode auxiliar no processo de sensibilização da população na prevenção de doenças.

Sobre o envolvimento dos postos de saúde em ações sociais realizadas na comunidade, os resultados foram os seguintes: $43 \%$ afirmaram que há envolvimento, $28 \%$ afirmaram desconhecer o envolvimento, e 29\% não souberam responder. Esses dados demonstram que há visibilidade por parte dos usuários em relação ao envolvimento dos postos de saúde em ações sociais na comunidade, segundo quase metade dos pesquisados, porém, há um percentual que desconhece o envolvimento. Isso mostra que há campo para ampliação de ações sociais por parte dos colaboradores dos serviços de saúde e que aquelas que já são realizadas precisam ser mais divulgadas à comunidade do entorno ou que o impacto dessas ações ainda é pequeno onde é realizado.

$\mathrm{Na}$ pesquisa, foi relatado por $43 \%$ das pessoas que há envolvimento dos colaboradores dos postos de saúde nas ações sociais. Assim, buscou-se identificar, também, quais os profissionais envolvidos nessas ações. Os pesquisados poderiam apontar um ou mais envolvidos, sendo citados os ACSs (89\%), enfermeira (65\%), auxiliares e técnicos de enfermagem (60\%), médico (36\%), dentista (32\%), auxiliares e técnicos em saúde bucal (26\%) e outros profissionais (20\%). Esses dados comprovam, mais uma vez, a importância da atuação dos ACSs, sendo os profissionais de saúde que estão mais perto da comunidade e, também, aponta que a equipe de enfermagem tem uma atuação de destaque, pois a mesma costuma ser a que mais atende a comunidade no posto de saúde.

Os profissionais da odontologia também estão começando a se envolver mais em ações, em especial na prevenção e tratamento de doenças bucais com grupos específicos, como gestante, bebês, crianças, adolescentes e idosos. Porém, os mesmos precisam se integrar mais com a equipe de enfermagem e médica nas ações sociais realizadas pelo posto de saúde, segundo os dados coletados.

A seguir, foi pesquisado sobre a realização de ações sociais nos municípios. Cerca de $77 \%$ afirmaram que são realizadas ações sociais e $23 \%$ afirmaram que não são realizadas ações sociais.

Sobre o foco das ações sociais, os temas são diversos, como: saúde, $3^{\text {a }}$ idade, educação, crianças e adolescentes, cultura, reabilitação de dependência química, proteção aos animais, segurança e prevenção de violência, meio ambiente, inclusão social, portadores de necessidades especiais, capacitação profissional e no esporte e lazer. 
Assim, percebe-se que o foco principal, segundo os pesquisados, são as ações de saúde, demonstrando a importância das mesmas nos municípios, em especial de pequeno porte, como é o caso dos que compõem a CIR - Itapeva - SP, pois os mesmos apresentam vários problemas relacionados à saúde pública, conforme os indicadores sociais e de saúde demonstrarão na próxima seção deste trabalho. Dessa forma, há margem para uma maior participação dos colaboradores de saúde nessas ações sociais.

E, por último, foi indagado aos pesquisados, quem são os responsáveis pelas ações sociais no município de sua residência. Os resultados foram: serviços de Assistência Social em parcerias com empresas/voluntários, unidades de saúde em parceria com empresas, Igrejas, voluntários independentes, Associações e ONGs, Escolas Públicas em parceria com empresas /voluntários e empresas do município.

Assim, os dados demonstram que há vários segmentos envolvidos nas ações sociais. É positivo o fato de $48 \%$ terem mencionado as unidades de saúde em parceria com outras pessoas, pois os colaboradores da unidade de saúde precisam ter um comprometimento com a comunidade do entorno para saber as suas reais necessidades e prioridades. A pesquisa apontou, também, que as empresas foram as menos citadas em relação às ações sociais, assim, fica a sugestão de que a Responsabilidade Social seja mais praticada pelas empresas dos municípios da CIR - Itapeva - SP. Em relação ao papel do Estado, especificamente no âmbito municipal, além de oferecer serviços de saúde pública de qualidade à população, os gestores municipais devem também, incentivar as ações sociais entre seus colaboradores.

Os 15 municípios que compõem a CIR Itapeva - SP apresentam em seus indicadores sociais e de saúde pública, dados que caracterizam a região como uma das menos desenvolvidas do Estado de São Paulo, segundo o IBGE, portal IDEB, portal Seade e portais oficiais dos municípios (2016).

A região da CIR Itapeva é pouco industrializada, poucos municípios têm indústrias em seu território. A maior parte dos municípios tem como atividade principal a agropecuária e a representatividade do Produto Interno Bruto (PIB) no Estado é relativamente baixa. A renda per capita é muito baixa quando comparada com a média nacional que em 2015 foi de $\mathrm{R} \$ 1.113,00$, segundo dados do IBGE. Quanto ao Índice de Desenvolvimento da Educação Básica (IDEB), os municípios superaram a média nacional para o $5^{\circ}$ ano, que foi de 5,5 (YAMAMOTO, 2016). Já em relação ao IDEB do $9^{\circ}$ ano, 11 municípios atingiram ou ultrapassaram a média nacional, sendo que 4 ficaram com índices menores. 
A taxa de analfabetismo de 13 municípios superou a média nacional que é de 8,5\% da população acima de 15 anos (IBGE, 2016). Somente os municípios de Itapeva e Itararé tiveram índices abaixo da média nacional (6,25 e 6,5\% respectivamente).

Em relação ao Índice de Desenvolvimento Humano (IDH), somente três municípios apresentam um IDH considerado alto: Apiaí, Itapeva e Itararé. Porém, mesmo estando nessa faixa de classificação, Itapeva, que apresenta o melhor IDH dos municípios da CIR, está na posição 370 no Estado de São Paulo. Oito dos municípios estão entre os últimos quinze com o menor IDH do Estado, sendo Ribeirão Branco o último colocado, com um IDH de 0,639.

Além dos indicadores sociais, apresentam-se alguns indicadores de saúde pública que compõem o Índice de Desempenho do Sistema único de Saúde (IDSUS), com o objetivo de avaliar o desempenho do sistema quanto ao cumprimento de seus princípios e diretrizes, com base nos dados dos Sistemas de Informação Nacionais do SUS (OLIVEIRA; SELLERA; REIS, 2013).

O IDSUS é composto por 24 indicadores que avaliam o acesso e efetividade na atenção básica, especializada ambulatorial e hospitalar, e de urgência e emergência (BRASIL, 2015).

Foram analisados dois indicadores do IDSUS: a cobertura populacional estimada pelas equipes de Atenção Básica e pelas equipes de saúde bucal. A taxa de mortalidade infantil não é contemplada no IDSUS, porém, por ser um parâmetro de relevância para a Organização Mundial de Saúde (OMS), a pesquisadora inclui este parâmetro na pesquisa.

O ranking do IDSUS vai de 0 a 10, sendo a média nacional 5,4 em 2015. A cobertura por equipes de saúde na Atenção Básica nos municípios deve ser de 100\%. Nos municípios pesquisados, nove municípios não apresentaram $100 \%$ de cobertura. Isso significa que faltam equipes de Estratégia de Saúde da Família nessas localidades para atender a comunidade. Uma unidade de saúde pode ter de uma a três equipes, dependendo do espaço físico existente. Além da falta de equipes, como alguns municípios possuem uma extensa área rural, existe a hipótese também que faltam unidades de saúde em pontos estratégicos do território.

Sobre a cobertura de equipes de saúde bucal, 11 municípios têm mais de $50 \%$ de seu território abrangido. Uma das hipóteses que pode explicar esse resultado são os incentivos de implantação de equipes de ESF em odontologia, nos últimos 10 anos, pelo Governo Federal. 
Quanto a taxa de mortalidade infantil, cinco municípios estão abaixo da média nacional, que em 2015 foi de 13,82 óbitos por mil nascidos vivos. Os outros 10 municípios têm índices acima da média nacional, o que é um fator preocupante, pois reflete problemas na assistência a gestante no pré-natal na Atenção Básica, e a na assistência no parto nos hospitais. Conforme foi apresentado no quadro 2, vários municípios da CIR não possuem assistência hospitalar, e apenas Itapeva possui UTI neonatal. Deve-se ressaltar também que, a distância de alguns municípios para a referência microrregional; alguns estão distantes a cerca de $200 \mathrm{~km}$ de Itapeva, e nem sempre há ambulâncias disponíveis para efetuar a transferência de pacientes de forma rápida, o que coloca em risco a vida de pessoas que necessitam de um atendimento mais especializado em urgências e emergências.

Embora existam problemas na saúde pública dos municípios brasileiros, há vários municípios que são referência em qualidade. O próximo tópico abordará dados desses municípios com referencial de excelência.

O IDH dos 14 municípios são considerados altos, pois estão na faixa acima de 0,700, apenas Campo Bonito - PR apresenta um índice considerado médio $(0,681)$.

Assim, os indicadores de forma geral são positivos nesses municípios. Quanto aos indicadores de saúde pública, o quadro 1 apresenta os dados.

Sobre a cobertura populacional de equipes na Atenção Básica, percebe-se uma diferença acentuada, se comparado com os municípios da CIR Itapeva. Apenas os municípios de Barueri -SP e Campo Bonito - PR não apresentam 100\% de cobertura. Deve-se destacar que Barueri atingiu uma nota alta no índice IDSUS devido a estrutura de especialidades, e hospitalar existente em seu município. Os outros 13 municípios apresentam um percentual acima dos $100 \%$. Isso na prática significa que há uma estrutura ampla de Atenção Básica nos municípios, o que resulta em atendimentos com agendamentos mais rápidos, mais profissionais para cuidarem da saúde Pública, menos sobrecarga dos serviços de urgência e emergência, que em muitos municípios acabam atendendo casos que poderiam ser resolvidos nas unidades básicas de saúde.

Quanto a cobertura das equipes de saúde bucal, 14 municípios ultrapassaram a média nacional de 50\%, com exceção de Barueri-SP, que tem uma cobertura de 45,6\%.

Quanto a taxa de mortalidade infantil, há um contraste nesses municípios. Enquanto que em Paulo Bento e Ipiranga do Sul, municípios do Estado do Rio Grande do Sul, a taxa é zero, há municípios com uma taxa relativamente alta como Arco-Íris (33,3\%) e Virmond - PR $(28,1 \%)$. Há vários questionamentos sobre a formulação do índice IDSUS, e um deles é sobre a não colocação da taxa de mortalidade infantil como um parâmetro, pois o que se utiliza é a taxa de óbitos nas internações em UTIs em menores de 15 anos. 
Quadro 1 - Indicadores de saúde pública do IDSUS dos 15 municípios classificados c/ a melhor saúde pública

\begin{tabular}{|c|c|c|c|c|c|}
\hline \multirow[t]{3}{*}{ MUNICÍPIO } & \multicolumn{4}{|c|}{ INDICADORES DE ATENÇÃO BÁSICA } & \multirow{3}{*}{$\begin{array}{l}\text { IDSUS } \\
\text { Município }\end{array}$} \\
\hline & \multirow{2}{*}{$\begin{array}{c}\text { Cobertura populacional } \\
\text { estimada pelas Equipes Básicas } \\
\text { de Saúde* (em \%) } \\
\text { Parâmetro de referência: } 100 \% \\
\text { Resultado }\end{array}$} & $\begin{array}{c}\text { Cobertura populacional } \\
\text { estimada pelas Equipes Básicas } \\
\text { de Saúde Bucal* (em \%) } \\
\text { Parâmetro de referência: } 50 \%\end{array}$ & \multicolumn{2}{|c|}{$\begin{array}{l}\text { Taxa de mortalidade Infantil } \\
\text { (por mil nascidos vivos) ** }\end{array}$} & \\
\hline & & Resultado & Resultado & Parâmetro & \\
\hline Arco-Íris - SP & 177,5 & 155,8 & 33,3 & 13,8 & 8,37 \\
\hline Pinhal - RS & 120,4 & 119,3 & 26,3 & 13,8 & 8,22 \\
\hline Barueri - SP & 62,6 & 45,6 & 13,3 & 13,8 & 8,21 \\
\hline Rosana-SP & 127,8 & 127,0 & 8,0 & 13,8 & 8,17 \\
\hline $\begin{array}{l}\text { Cássia dos } \\
\text { Coqueiros - SP }\end{array}$ & 142,7 & 190,3 & 9,8 & 13,8 & 8,13 \\
\hline Paulo Bento - RS & 179,1 & 227,7 & 0 & 13,8 & 8,13 \\
\hline $\begin{array}{l}\text { São João Batista do } \\
\text { Glória - MG }\end{array}$ & 101,2 & 112,5 & 18,7 & 13,8 & 7,94 \\
\hline $\begin{array}{l}\text { Santa Rita d'Oeste } \\
\text { - SP }\end{array}$ & 199,9 & 196,6 & 6,8 & 13,8 & 7,94 \\
\hline Virmond - PR & 186,1 & 151,9 & 28,1 & 13,8 & 7,93 \\
\hline Altinópolis -SP & 128,7 & 99,6 & 10,5 & 13,8 & 7,89 \\
\hline Pardinho - SP & 106,1 & 89,6 & 8,35 & 13,8 & 7,89 \\
\hline $\begin{array}{l}\text { Três Fronteiras - } \\
\text { SP }\end{array}$ & 153,5 & 55,3 & 12,6 & 13,8 & 7,83 \\
\hline $\begin{array}{l}\text { Águas Mornas - } \\
\text { SC }\end{array}$ & 141,2 & 113,6 & 1,7 & 13,8 & 7,82 \\
\hline $\begin{array}{l}\text { Ipiranga do Sul - } \\
\text { RS }\end{array}$ & 155,8 & 133,7 & 0 & 13,8 & 7,82 \\
\hline $\begin{array}{l}\text { Campo Bonito - } \\
\text { PR }\end{array}$ & 75,6 & 90,8 & 22,95 & 13,8 & 7,81 \\
\hline
\end{tabular}

Fonte: Portal IDSUS, IBGE, portal Seade (2016), sites oficiais dos Estados de SC e RS.

* Dados do IDSUS de 2011, sendo o parâmetro utilizado o nacional.

** Dados do IBGE de 2015, sendo utilizado o parâmetro nacional de 2015.

Quanto a cobertura das equipes de saúde bucal, 14 municípios ultrapassaram a média nacional de 50\%, com exceção de Barueri-SP, que tem uma cobertura de 45,6\%.

Quanto a taxa de mortalidade infantil, há um contraste nesses municípios. Enquanto que em Paulo Bento e Ipiranga do Sul, municípios do Estado do Rio Grande do Sul, a taxa é zero, há municípios com uma taxa relativamente alta como Arco-Íris (33,3\%) e Virmond - PR $(28,1 \%)$. Há vários questionamentos sobre a formulação do índice IDSUS, e um deles é sobre a não colocação da taxa de mortalidade infantil como um parâmetro, pois o que se utiliza é a taxa de óbitos nas internações em UTIs em menores de 15 anos. 
Assim, ao analisar os dados dos municípios, percebe-se que o aumento da cobertura de equipes na Atenção básica pode ser uma das hipóteses que explique o aumento da qualidade dos serviços de saúde pública em um município, além das condições socioeconômicas da população.

\section{Considerações Finais}

Este artigo teve como objetivo apresentar um estudo sobre as ações sociais e os serviços de saúde pública dos 15 municípios que compõem a CIR Itapeva. Inicialmente, a revisão de literatura ressaltou a importância das ações sociais provenientes do Empreendedorismo Social para uma comunidade. Na sequência, apresentaram-se aspectos da estrutura básica dos serviços do SUS oferecidos à população brasileira na Atenção Básica, Especializada e Hospitalar. Na abordagem sobre gestão em saúde, destacou-se a importância da descentralização na gestão municipal em saúde, bem como a necessidade do Governo em ser empreendedor.

O estudo de caso relatou dados obtidos pela realização de entrevistas semiestruturadas com os usuários dos 15 municípios da CIR Itapeva-SP.

E, por fim, apresentou-se uma descrição e análise da organização da saúde pública nos munícipios da CIR Itapeva - SP, parte integrante da Divisão Regional de Saúde (DRS) de Sorocaba, Estado de São Paulo, por apresentar indicadores socioeconômicos dos municípios, e alguns indicadores de saúde Pública que compõem o IDSUS. Esses dados foram comparados com os dos municípios com melhor desempenho no IDSUS, para identificar possíveis hipóteses que garantiram o bom resultado.

Em resposta ao problema de pesquisa que indagou sobre as ações sociais por parte dos colaboradores dos serviços de saúde pública nos 15 municípios da CIR Itapeva -SP, identificou-se que há envolvimento dos mesmos, na percepção dos usuários, envolvimento em especial dos Agentes Comunitários de saúde, e Equipe de Enfermagem.

As práticas sociais citadas são semelhantes nos municípios, prevalecendo às ações em Saúde, Educação e Pessoas da Terceira Idade. E, mesmo aqueles que afirmaram que não há envolvimento específico dos colaboradores da Saúde Pública, reconheceram que são feitas ações em seu município, por segmentos diversos, incluindo do Setor Público. A pesquisa também apontou que empresas e financiamentos privados tiveram pouca participação no envolvimento com a população, quando o tema é saúde. Igrejas, associações do bairro, voluntários independentes e ONGs possuem maior relevância no apoio aos cidadãos. 
O comparativo dos 15 municípios da CIR Itapeva com os 15 municípios que possuem o índice IDSUS mais elevado, demonstrou que as condições socioeconômicas existentes no município se refletem na qualidade da Saúde da população. Porém, pode-se mencionar que a ampla cobertura de equipes na Atenção Básica pode fazer a diferença na assistência à saúde, proporcionando maior acesso.

Assim, conclui-se, com base na delimitação de pesquisa realizada neste trabalho, que é de suma importância o investimento na Atenção Básica, pela criação de novas estruturas, bem como o aperfeiçoamento das já existentes. E, também, que ações sociais entre colaboradores e comunidade local precisam ser incentivadas, fomentadas e, que ações já existentes nesses municípios, podem ter a participação de tais pessoas, porém, falta percepção da parte de gestores e de usuários desse trabalho realizado, seja por falta de informação ou de divulgação nos meios de comunicação.

Sugerem-se para futuras pesquisas, outros estudos relacionados a CIR Itapeva-SP com a análise de todos os 24 indicadores do IDSUS dos municípios. Como recomendação adicional destaca-se a aplicação do roteiro de pesquisa com a percepção das ações sociais pelos colaboradores de saúde pública nos postos de saúde desses municípios, comparando com as percepções dos gestores e dos usuários, e estudos das ações sociais das entidades e ONGs que atuam na área de saúde. 


\section{Referencial Bibliográfico}

ÁGUAS MORNAS. Disponível em: <http://guia.fecam.org.br/municipios/lista_municipios.php?letra=a〉. Acesso em: 2 nov. 2016.

AGUIAR, Z. N. SUS: Sistema Único de Saúde - antecedentes, percurso, perspectivas e desafios. 2 ed. São Paulo: Martinari, 2015.

ALTINÓPOLIS. Disponível em:

<http://ideb.inep.gov.br/resultado/resultado.seam?cid=3236583>. Acesso em: 2 nov. 2016.

APIAÍ. Disponível em:<http://www.deepask.com/goes?page=apiai/sp-confira-os-indicadoresmunicipais-e-dados-demograficos-sociais-e-economicos-do-seu-municipio>. Acesso em: 2 nov. 2016.

ARCO-ÍRIS. Disponível em:〈http://www.arcoiris.sp.gov.br〉. Acesso em: 18 nov. 2016.

AUSTIN, J. E. Parcerias: fundamentos e benefícios para o terceiro setor. Tradução: Lenke Peres. São Paulo: Futura, 2001.

BAGEENSTOSS, S.; DONADONE, J. C. Empreendedorismo social: reflexões acerca do papel das organizações e do Estado. Revista Gestão e Sociedade, Belo Horizonte - MG, v. 7, n. 16, janeiro/abril 2013, p. 112-131.

BARDIN, L. Análise do Conteúdo. Tradução: Luís Antero Reto e Augusto Pinheiro. São Paulo: Edições 70, 2011.

BARRA DO CHAPÉU. Disponível em:

<http://cidades.ibge.gov.br/xtras/perfil.php?lang=\&codmun=350535\&search=sao-paulo|barrado-chapeu>. Acesso em: 25 set. 2016.

BARUERI. Disponível em:<http://www.barueri.sp.gov.br>. Acesso em: 18 nov. 2016.

BOM SUCESSO DE ITARARÉ. Disponível em:

$<$ http://cidades.ibge.gov.br/xtras/perfil.php?lang=\&codmun=350715\&search=sao-paulo|bomsucesso-de-itarare>. Acesso em: 25 set. 2016.

BRASIL. Constituição da República Federativa do Brasil: texto constitucional promulgado em 5 de outubro de 1988, com as alterações adotadas pelas Emendas Constitucionais n. 1/92 a 56/2007 e pelas Emendas Constitucionais de Revisão n. 1 a 6/94. Brasília: Senado Federal, Subsecretaria de Edições Técnicas, 2008.

BRASIL. Conselho Nacional de Secretários de Saúde - CONASS. Sistema Único de Saúde. Coleção para entender a Gestão do SUS. Vol. I. Brasília: CONASS, 2011.

BRASIL. Índice de Desempenho do Sistema único de Saúde (IDSUS). Brasília-DF: Ministério da Saúde, 2015.

BRASIL. Ministério da Saúde. O SUS no seu município: garantindo saúde para todos. Coordenação: PEREIRA, A. L. et al. Brasília: Ministério da Saúde, 2004.

BRASIL. Ministério da Saúde. Secretaria de Atenção Básica. Departamento de Atenção Básica. Política Nacional de Atenção Básica. Brasília: Ministério da Saúde, 2012. 
BURI. Disponível em:

<http://cidades.ibge.gov.br/xtras/perfil.php?lang=\&codmun=350800\&search=sao-paulo|buri $>$. Acesso em: 25 set. 2016.

CADASTRO NACIONAL DOS ESTABELECIMENTOS DE SAÚDE (CNES). Disponível em: $<$ http://cnes2.datasus.gov.br/lista_tot_es_municipio.asp?estado=35\&nomeestado=sa0\%2opa ulo>. Acesso em: 25 set. 2016.

CAMPO BONITO. Disponível em:<http://www.campobonito.pr.gov.br/>. Acesso em: 20 nov. 2016.

CAMPOS, J. Q.; PRESOTO, L. H.; SOUZA, A. M. Pesquisa de Campo em Ciências da Saúde. São Paulo: Centro de Estudos em Saúde, 2012.

CÁSSIA DOS COQUEIROS. Disponível

em:<http://www.cassiadoscoqueiros.sp.gov.br/novo_site/site/index.php?pagina=internas\&exibir $=$ secoes $\&$ IDITEM=16>. Acesso em: 2 nov. 2016.

CRUZ, G. As duas faces do empreendedorismo social. Revista Eletrônica do Mestrado em Administração da Universidade Potiguar - RAUNP, Natal-RN, ano V, n. 1, out 2012/ mar. 2013, p. 9 - 20.

DATASUS. Óbitos por residência por região de Saúde (CIR) segundo município. Disponível em:<http://tabnet.datasus.gov.br/cgi/tabcgi.exe?sim/cnv/obt10sp.def>. Acesso em: 18 nov. 2016.

DEES, J. G. The Meaning of Social Entrepreneurship. 2001. Kauffman Foundation and Stanford University, Kansas City, 2001. Disponível em: <https://entrepreneurship.duke.edu/newsitem/the-meaning-of-social-entrepreneurship/>. Acesso em: 2 ago. 2016.

DOLABELA, F. Oficina do empreendedor. Rio de Janeiro: Sextante, 2008

FISCHER, R. M. Empreendedorismo social: apontamentos para um debate. In: CENTRO RUTH CARDOSO. (Organização) Políticas Sociais - Ideias e Práticas. São Paulo: Moderna, 2011.

FLEURY, S. Democracia e inovação na gestão local da saúde. Rio de Janeiro: Cebes/ FIOCRUZ, 2014.

FUNDAÇÃO DE ECONOMIA E ESTATÍSTICA (FEE). Disponível em:<http://www.fee.rs.gov.br/perfil-socioeconomico/municipios/>. Acesso em: 2 nov. 2016.

FUNDAÇÃO DO DESENVOLVIMENTO ADMINISTRATIVO (FUNDAP). Programa decenal para a área social em São Paulo. Gestão pública no setor saúde: um plano estratégico. São Paulo: FUNDAP, 1992.

GATES FOUNDATION. Disponível em:<http://www.gatesfoundation.org>. Acesso em: 25 nov. 2016.

GEOTÉCNICA PLANEJAMENTO TECNOLÓGICO. Delimitação geográfica dos 15 municípios da CIR - Itapeva-SP. Itararé: GEOTÉCNICA, 2016.

GIL, A. C. Como elaborar Projetos de Pesquisa. 4 ed. São Paulo: Atlas, 2009.

GONÇALVES, H. A. C.; LOPES, M. H. A dignidade da pessoa humana e o valor social do trabalho. Revista Direito Econômico Socioambiental, Curitiba, v. 4, n.2, p. 129-145, jul/dez 2013.

GUAPIARA. Disponível em:<http://www.guapiara.sp.gov.br/historico.htm>. Acesso em: 2 nov. 2016. 
GUAPIARA. Disponível em:<http://www.deepask.com/goes?page=guapiara/sp-confira-osindicadores-municipais-e-dados-demograficos-sociais-e-economicos-do-seu-municipio >

Acesso em: 2 nov. 2016.

ÍNDICE de Desempenho do Sistema Único de Saúde (IDSUS). Disponível em:<http://idsus.saude.gov.br/mapas.html>. Acesso em: 30 out. 2016.

INSTITUTO BRASILEIRO DE GEOGRAFIA E ESTATÍSTICA (IBGE). Estimativas da população residente nos municípios brasileiros com data de referência em $1^{\circ}$ de julho de 2015 . Disponível em:

<http://www.ibge.gov.br/home/estatistica/populacao/estimativa2015/estimativa_dou.shtm>. Acesso em: 30 ago. 2016.

INSTITUTO ETHOS. Disponível em:<http://www.ethos.org.br>. Acesso em: 29 nov. 2016.INSTITUTO PARANAENSE DE DESENVOLVIMENTO ECONÔMICO E SOCIAL (IPARDES). Dados municípios Paraná. Disponível em:

<http://www.ipardes.gov.br/index.php?pg_conteudo=1\&cod_conteudo=29>.Acesso em: 2 nov. 2016.

ITABERÁ. Disponível em:

$<$ http://cidades.ibge.gov.br/xtras/perfil.php?lang=\&codmun=352170\&search=sao-

paulo|itabera>. Acesso em: 25 set. 2016

ITAÓCA. Disponível em:

<http://cidades.ibge.gov.br/xtras/perfil.php?lang=\&codmun=352215\&search=sao-paulo|itaoca>. Acesso em: 25 set. 2016.

ITAPEVA. Disponível em:

$<$ http://cidades.ibge.gov.br/xtras/perfil.php?lang=\&codmun=352240\&search=saopaulolitapeva>. Acesso em: 25 set. 2016.

IPIRANGA DO SUL. Disponível

em: $<$ http://www.fee.rs.gov.br/perfilsocioeconomico/municipios/detalhe/?municipio=ipiranga $+\mathrm{d}$ o+sul>. Acesso em: 2 nov. 2016

ITAPIRAPUÃ PAULISTA. Disponível em:

$<$ http://cidades.ibge.gov.br/xtras/perfil.php?lang=\&codmun=352265\&search=saopaulo|itapirapua-paulista>. Acesso em: 25 set. 2016.

ITARARÉ. Disponível em:

$<$ http://cidades.ibge.gov.br/xtras/perfil.php?lang=\&codmun=352320\&search=saopaulo|itarare>. Acesso em: 25 set. 2016.

JUNQUEIRA, L. A. P. A descentralização e a Gestão Municipal da Política de Saúde. Revista Ciência e Saúde Coletiva, Rio de Janeiro, n. 1, 1996, p. 21-22.

JUNQUEIRA, L. A. P. Novas Formas de Gestão na Saúde: descentralização e intersetorialidade. Revista Saúde e Sociedade, São Paulo, n. 2, 1997, p. 31-46.

LEAL, A. L. C. A.; FREITAS, A. A. F.; FONTENELE, R. E. S. Criação de valor no empreendedorismo social: evidências a partir da comparação com o empreendedorismo comercial. Revista Gestão Social e Ambiental - RGSA, São Paulo, v.9, n.1, p. 51-65, jan/abr 2015.

LEMOS, R.S. de. A valorização do trabalho humano: fundamento da república, da ordem econômica e da ordem social na constituição brasileira de 1988. Revista Páginas de Direito, Porto Alegre, ano 15, n.1261, 25 de junho de 2015. 
MARCONI, M. A.; LAKATOS, E. M. Fundamentos de Metodologia Científica. 6 ed. São Paulo: Atlas, 2007.

MORGAN, G. Imagens da Organização. Tradução: Geni G. Goldschmidt. 2 ed. São Paulo: Atlas, 2007.

NICHOLLS, A. (org.). Social Entrepreneurship: new models of sustainable social change. London: Oxford University Press, 2006

NOVA CAMPINA. Disponível em:<http://www.novacampina.sp.gov.br/historia/>. Acesso em: 2 nov. 2016.

OLIVEIRA, A. B. S. (coord.). Métodos e Técnicas de Pesquisa em Contabilidade. São Paulo: Saraiva, 2003.

OSBORNE, D.; GAEBLER, T. Reinventando o governo: como o espírito empreendedor está transformando o setor público. Tradução: Sérgio Fernando Guarischi Bath e Ewandro Magalhães. 5 ed. Brasília: MH Comunicação, 1995.

PARDINHO. Disponível em:<http://www.pardinho.sp.gov.br/>. Acesso em: 20 nov. 2016.

PAULO BENTO. Disponível

em:<http://www.paulobento.rs.gov.br/site/municipio/page?pagename=dadosindicadores $>$.

Acesso em:18 nov. 2016.

PEREDO, A. M. Social Entrepreneurship. The Encyclopedia of Entrepreneurship, L.P. Dana, ed., Edward Elgar, Forthcoming. 2006.

PINHAL. Disponível em:<http://www.pinhal.rs.gov.br>. Acesso em: 2 nov. 2016.

PINHO, J. C.; THOMPSON, D. Condições estruturais empreendedoras na criação de novos negócios: a visão de especialistas. Revista de Administração de Empresas - RAE, São Paulo, v. 56, n.2, mar-abr 2016, p. 166-181.

RAMOS, Guerreiro. Uma introdução ao histórico da organização racional do trabalho. Brasília: Conselho Federal de Administração, 2008.

REIS, D. O.; ARAÚJO, E. C. de; CECÍLIO, 1. C. O. Políticas públicas de saúde: Sistema Único de Saúde. São Paulo: Unifesp, 2012.

RIBEIRA. Disponível

em: <http://cidades.ibge.gov.br/xtras/perfil.php?lang=\&codmun=354280\&search=sao-

paulo|ribeira>. Acesso em: 25 set. 2016.

RIBEIRÃO BRANCO. Disponível em:<http://ribeiraobranco.sp.gov.br/sobre-o-municipio/>. Acesso em: 2 nov. 2016.

RIO GRANDE DO SUL. Rio Grande do Sul reduz mortalidade infantil e materna. 2014. Disponível em:<http://www.rs.gov.br/conteudo/208562/rio-grande-do-sul-reduz-mortalidadeinfantil-e-materna>. Acesso em: 2 nov. 2016.

RIVERSUL. Disponível

em: <http://cidades.ibge.gov.br/xtras/perfil.php?lang=\&codmun=354350\&search=saopaulo|riversul>. Acesso em: 25 set. 2016.

RIVERSUL. Disponível em:<http://www.riversul.sp.gov.br/72/dadosmunicipais/>. Acesso em: 2 nov. 2016.

ROSANA. Disponível em: $<$ http://ideb.inep.gov.br/resultado/resultado.seam?cid=3236583 $>$. Acesso em: 2 nov. 2016. 
ROSANA. Disponível em:<http://cidades.ibge.gov.br/painel/painel.php?codmun=354425>. Acesso em: 18 nov. 2016.

SANTA CATARINA. SC tem a maior expectativa de vida e a menor taxa de mortalidade infantil do país, revela IBGE. 2014. Disponível em: <http://www.sc.gov.br/mais-sobre-saude/11756-ibgerevela-que-sc-tem-a-maior-expectativa-de-vida-e-a-menor-taxa-de-mortalidade-infantil-dopais>. Acesso em: 2 nov. 2016.

SANTA RITA D' OESTE. Disponível em:

<http://santaritadoeste.municipios.sp.gov.br/portal/site/municipios/menuitem.cbb5d738487b2b7 eb1249cc5e2308ca0/?vgnextoid=c1e7ea0ca3191310VgnVCM1000004c03c80aRCRD\&vgnextf $\mathrm{mt}=$ default $>$. Acesso em: 2 nov. 2016.

SÃO JOÃO BATISTA DO GLÓRIA. Disponível em: $<$ http://cidades.ibge.gov.br/xtras/temas.php?iang=codmun=316220\&idtema=118\&search=m inas-gerais/sao-joao-batista-do-gloria\%c3\%8indice-de-desenvolvimento-humano-municipalidhm->. Acesso em: 2 nov. 2016.

SÃO PAULO (Estado). Comissão Intergestores Bipartite. Disponível em: $<$ http://www.saude.sp.gov.br/ses/institucional/orgaos-vinculados/comissao-intergestoresbipartite-cib/apresentacao>. Acesso em: 18 nov. 2016.

SÃO PAULO (Estado). Decreto n. 52.182 de 16 de julho de 1969. Dispõe sobre a organização da Secretaria de Estado da Saúde e dá outras providências. Disponível em:<http://www.al.sp.gov.br/repositorio/legislacao/decreto/1969/decreto-52182-

16.07.1969.html>. Acesso em: 10 set. 2016.

SÃO PAULO (Estado). Regiões de Saúde. Disponível em:<http://sistema.saude.sp.gov.br/tabnet/deftohtm.exe?MORTINF.def>. Acesso em: 18 nov. 2016.

SÃO PAULO (Estado). Secretaria de Estado de São Paulo. Regionais de Saúde. Disponível em: $<$ http://www.saude.sp.gov.br/ses/institucional/departamentos-regionais-de-saude/regionaisde-saude>. Acesso em: 28 set. 2016.

SISTEMA ESTADUAL DE ANÁLISE DE DADOS (SEADE). Dados Mortalidade Infantil Estado de São Paulo. Disponível em:<http://www.seade.gov.br/produtos/mortalidade-infantil/>. Acesso em: 18 nov. 2016.

SOLA, L. Políticas sociais na trilha da política. In: CENTRO RUTH CARDOSO. (Organização) Políticas Sociais - Ideias e Práticas. São Paulo: Moderna, 2011.

TACHIZAWA, T. Organizações Não Governamentais e Terceiro Setor: criação de ONGs e estratégias de atuação. 6 ed. São Paulo: Atlas, 2014.

TACHIZAWA, T.; CRUZ JÚNIOR, J. B.; ROCHA, J. A. O. Gestão de Negócios: visões e dimensões empresariais da organização. 3 ed. São Paulo: Atlas, 2006.

TAQUARIVAÍ. Disponível em:

$<$ http://cidades.ibge.gov.br/xtras/perfil.php?lang=\&codmun=355385\&search=sao-

paulo|taquarivai>. Acesso em: 25 set. 2016.

TRÊS FRONTEIRAS. Disponível em:

<http://ideb.inep.gov.br/resultado/resultado.seam?cid=3237140>. Acesso em: 2 nov. 2016.

TRÊS FRONTEIRAS. Disponível em:<http://www.tresfronteiras.sp.gov.br/>. Acesso em: 20 nov. 2016.

VERGARA, S. C. Métodos de Pesquisa em Administração. 5 ed. São Paulo: Atlas, 2012. 
VIRMOND. Disponível em:<http://www.virmond.pr.gov.br/>. Acesso em: 2 nov. 2016.

YAMAMOTO, B. K. Ideb 2015: "Nota" da educação continua ruim, principalmente no ensino médio. Disponível em:<http://educacao.uol.com.br/noticias/2016/09/08/ideb-2015-nota-daeducacao-continua-ruim-principalmente-no-ensino-medio.htm>. Acesso em: 18 nov. 2016.

YIN, R. K. Estudo de caso: planejamento e métodos. Tradução: Ana Thorell. 4 ed. Porto Alegre: Bookman, 2010.

YOUNG, R. For What It Is Worth: Social Value and the Future of Social Entrepreneurship. In: NICHOLLS, A. (org.). Social Entrepreneurship: new models of sustainable social change. London: Oxford University Press, 2006.

YUNUS, M. Social Business Entrepreneurs are the Solution. In: NICHOLLS, A. (org.). Social Entrepreneurship: new models of sustainable social change. London: Oxford University Press, 2006. 